\title{
A FRAMEWORK AND INDICATORS FOR MEASURING THE IMPACT OF HEALTH RESEARCH ON THE HEALTH SECTOR IN VIETNAM
}

\author{
Thoai Dang Nguyen ${ }^{1}$, Thuy Phan Chung Tran², Hiep Tung Bui ${ }^{3, *}$ \\ ${ }^{1}$ Department of Pharmaceutics and Biopharmaceutics, Faculty of Pharmacy, Pham Ngoc Thach University of \\ Medicine, Ho Chi Minh City 700000, Vietnam \\ ${ }^{2}$ Ear-Nose-Throat Hospital, Ho Chi Minh City 700000, Vietnam \\ ${ }^{3}$ Department of Pharmacology and Clinical Pharmacy, Faculty of Pharmacy, Pham Ngoc Thach University of \\ Medicine, Ho Chi Minh City 700000, Vietnam \\ *Corresponding Author: Hiep Tung Bui (PhD.) \\ Department of Pharmacology and Clinical Pharmacy, Faculty of Pharmacy, \\ Pham Ngoc Thach University of Medicine, Ho Chi Minh City 700000, Vietnam \\ Address: 01 Duong Quang Trung Street, Ward 12, District 10, Ho Chi Minh City 70000, Vietnam \\ Email: buitunghiep2@gmail.com
}

Received 15 January 2018 - Revised 26 February 2018 - Accepted 14 March 2018

\begin{abstract}
This paper recounts the approach adopted in this research for the development of a framework and indicators designed to measure the impact of health research on the health sector of Vietnam. For this purpose, consultations were carried out with national and international agencies, key challenges in the development of the methodology were identified and various requirements were established. The proposed outcomes framework encompasses methodological guidelines, definitions of key concepts, the key health research effects identified by different stakeholders and the concerns raised by each stakeholder group. Five categories of health research benefits were established on the basis of the range of effects from such scholarship, information sources and related issues. The analysis of issues suggested the need to measure both impact and performance, with these measurements revolving around research success and effects that encourage funding agencies to continue supporting health research for knowledge development.
\end{abstract}

Keywords: indicator, investment, framework, healthcare, measurement, Vietnam.

\section{INTRODUCTION}

Governments prioritise value and accountability in the use of public funds, thereby rendering fund quantification a challenge. To address this problem, this research developed a framework and indicators for ascertaining the effects of health research on the health sector in Vietnam and advancing the establishment of certain benchmarks over time. ${ }^{1}$ The broader mandate of the sector includes excelling in the adherence to internationally accepted standards for the creation of new knowledge, the interpretation of improved healthcare services and the overall strengthening of the healthcare setup of the country. Recent years have witnessed an increase in health research investment in Vietnam, with the government proactively fostering these scholarly endeavours to cater to important health issues. Multidisciplinary research has also been encouraged, and both open and strategic exploratory projects are supported, especially in important fields. ${ }^{2,3}$

The rest of the paper is structured as follows. The second and third sections discuss the review of methods and the framework, respectively. The fourth section describes the selected indicators, and the final section concludes the paper. 


\section{BACKGROUND AND DEVELOPMENT OF THE FRAMEWORK}

In the Vietnam health sector, the regular evaluation of healthcare research and the documentation of its benefits are implemented to clear the way for assessing the overall economic, social and scientific effects of such scholarship. The current work enlisted the assistance of a team of experts to review the present level of knowledge regarding measurements of health research effects in the country to enable the establishment of our concept-based framework. High-level stakeholders scrutinised the proposed framework, identified expected principal impacts from research related to the health sector and evaluated the process by which such studies exert effects. ${ }^{4}$ The analysis also included various other factors, such as information sources and the concerns of primary stakeholders, as well as a few indicators that have been refined, updated and published. Focus was directed towards the optimum use of every indicator and the possible incorporation of other indices to ensure the availability of approaches and data.

Table 1: Research Themes

\begin{tabular}{l|l}
\hline \multicolumn{2}{c}{ CIHR Institutes } \\
\hline Original peoples' health & Human development, youth and child \\
Ageing & Health \\
Cancer research & Immunity and infection \\
Circulatory and respiratory Health & Arthritis and musculoskeletal health \\
Gender and health & Mental health and neurosciences \\
Genetics & Addiction \\
Health services and policy Research & Nutrition, diabetes and metabolism \\
\hline \multicolumn{2}{c}{ Research Themes (Pillars) } \\
\hline Biomedical research & Policy research and health services \\
Clinical research & Public and population health research \\
\hline
\end{tabular}

The experts reviewed the objectives of health research funding and the measurement of related challenges, which ultimately revealed various similarities in terms of funding aims. Common funding objectives are the creation of knowledge, the translation of knowledge and the development of human resources. The experts also agreed on the identification of challenges related to the effects of health research. For example, tracing the association between health research outcomes and outputs is very difficult given that knowledge develops over a long period of time. Outcomes, such as human potential, capacity and longevity, are also intangible. Different stakeholders have different priorities, including industrial improvement and commercialisation.

Various factors were considered in the development of the framework; these determinants are existing performance, mandated research themes, the requirement for a range of measurement approaches and a continuum of activity. We need to consider short-and long-term effects and adequately distinguish between the commercial and social use of methodologies. Indicators also need appropriate and regular updating with the interests of funding agencies in mind to achieve efficiency and increase insights through comparative analysis and effort pooling.

\section{STAKEHOLDERS}

Some concerns are common across all stakeholders, whereas others are unique to certain stakeholders. The higher education sector, for example, focuses on academic excellence, but all members of a given society are interested in improving health. Addressing these concerns involves monitoring the effects of health status indicators every year in accordance with health system orientations. ${ }^{2,3}$ Details regarding the varying concerns raised by the stakeholders in this work are presented in Table 2.

Table 2: Concerns of Stakeholders

\begin{tabular}{|c|l|}
\hline Stakeholders & \multicolumn{1}{c|}{ Concerns } \\
\hline Higher education sector & Academic excellence \\
\hline
\end{tabular}




\begin{tabular}{|c|l|}
\multirow{4}{*}{$\begin{array}{c}\text { Health professionals and } \\
\text { administrators }\end{array}$} & Knowledge production \\
\cline { 2 - 3 } & Capacity building \\
\cline { 2 - 2 } & Productivity of healthcare system resources \\
\hline \multirow{2}{*}{ Society } & Improved health status \\
\cline { 2 - 3 } & New treatment options for various diseases \\
\cline { 2 - 3 } & Arresting public healthcare threats \\
\cline { 2 - 3 } & Sustainability and efficiency \\
\hline \multirow{2}{*}{ Business sector } & Commercial potential \\
\hline \multirow{2}{*}{ Government } & Public health and responses to threats \\
\cline { 2 - 3 } & Health status \\
\cline { 2 - 3 } & Contribution to productivity and macroeconomic growth \\
\cline { 2 - 3 } & Sustainability and efficiency of private and public health systems \\
\hline
\end{tabular}

\section{TYPES OF IMPACT}

Graham put forward five benefit categories for incorporation into a health outcomes framework. ${ }^{4}$ These categories comprise knowledge production (scientific literature), research target and capacity, research projectability, research skills development, existing research utilisation, the benefits of ill health prevention, improved treatment options, economic benefits, the administrative effects of research and clinical and government policies. ${ }^{4}$ The economic category covers benefits such as discovering commercialisation, earning human capital gains and acquiring direct cost savings. No separate category was formulated for social benefits, but in the health sector, these advantages are considered to be analogous to economic benefits.5,6 The development of data approaches, data availability and merits are shown in Table 3.

Table 3: Various Indicators

\begin{tabular}{|cl|c|}
\hline \multicolumn{2}{|c|}{ Knowledge Production } \\
\hline 1. & $\begin{array}{l}\text { Number and impact of publications resulting } \\
\text { from research }\end{array}$ & \multirow{2}{*}{ Bibliometric studies } \\
\hline 2. & Citation impact analysis \\
\hline \multicolumn{2}{|c|}{ Research Target and Capacity } \\
\hline 1. & $\begin{array}{l}\text { Institutional influence on policy, research } \\
\text { and/or practice agendas }\end{array}$ \\
\hline 2. & Percentage of research chairholders & Evaluations every 3-5 years \\
\hline 3. & PhD graduates (type and number) & Stakeholder database \\
\hline 4. & PhD graduates planning postdoctoral fellowship \\
\hline \multicolumn{2}{|c|}{ Information Policy } \\
\hline
\end{tabular}




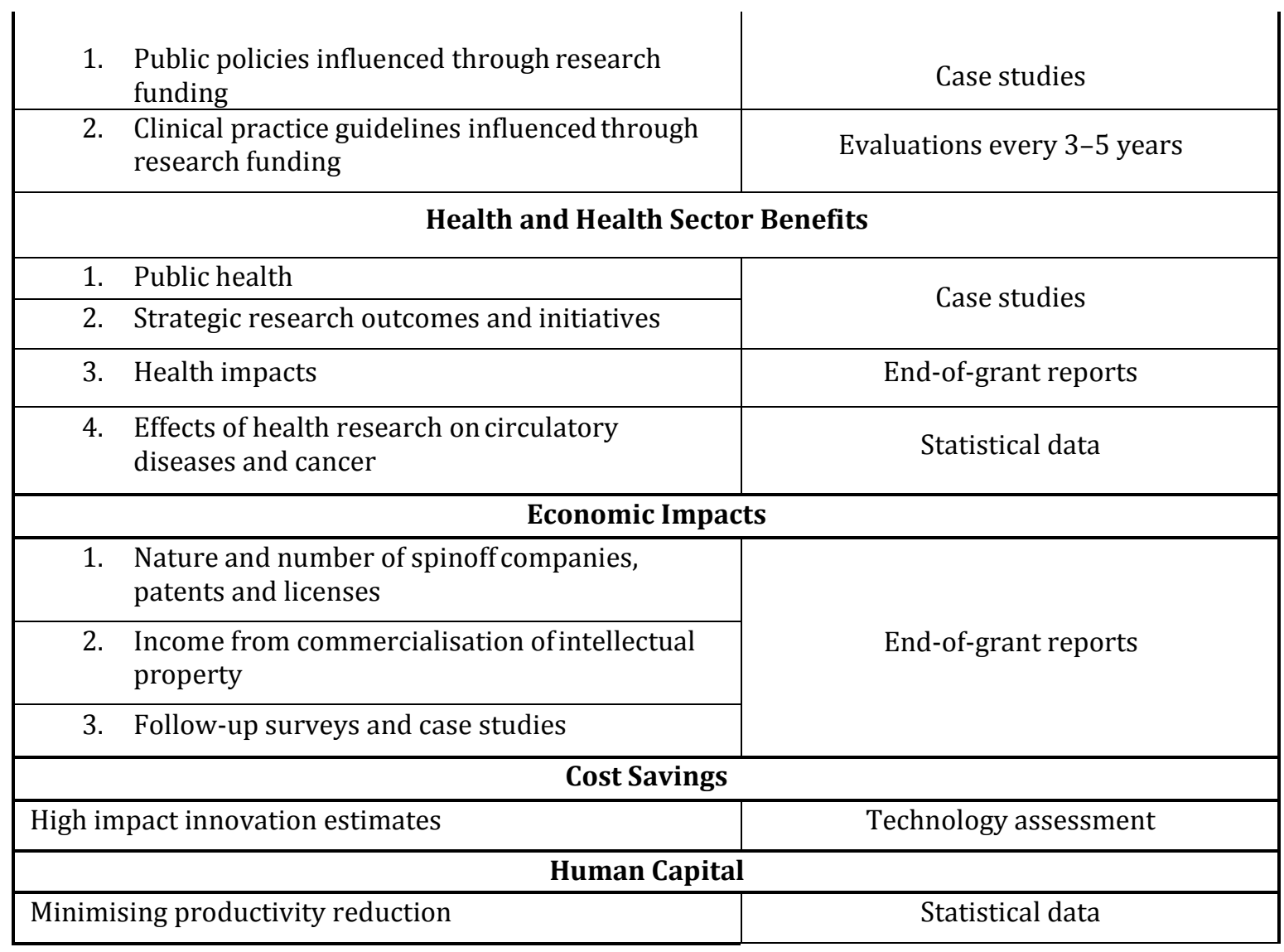

The importance of urgent approaches is also shown in the table above to clarify desirable information types and potential information sources.

\section{ATTRIBUTION ISSUES}

An individual researcher can claim credit for engendering direct research benefits, and funding enables research teams to create knowledge and stimulate associated effects. Special challenges determine the proportion of resources allocated by funding agencies because these also shape research agendas. Funding agencies encourage scholars to strive for compliance with stringent policies and scientific perspectives. These institutions also allocate up to 30 percent of funding to strategic research competitions. Finally, a number of short and long-term effects of health research are outcomes of the combination of factors, including new research knowledge approaches and environmental determinants.

Table 4: Performance Measurement Indicators

\begin{tabular}{|c|c|}
\hline Indicator & Variables \\
\hline Budget expenditure distribution & Funding programme type, area of research and operational expenses \\
\hline Institute evaluations & Effectiveness, delivery and relevance, along with mandates and \\
priorities
\end{tabular}




\begin{tabular}{|c|c|} 
Research grants & Success, value and number (research area) \\
\hline Investigators supported & Number of investigators (grant type and award) \\
\hline Collaboration & Team size and grant percentage \\
\hline Capacity building & $\begin{array}{c}\text { Salary awards (success rates, value and number) in a particular } \\
\text { research area }\end{array}$ \\
\hline Commercialisation & Amount and awards for commercial funding \\
\hline Partnerships & Number and value of partners (sector-wise contribution) \\
\hline Knowledge translation & Grant percentage \\
\hline
\end{tabular}

\section{IMPACT INDICATORS}

The impact indicators considered in this work are a combination of indices intended to measure both results and performance. Each of these indicators is comprehensively discussed in the succeeding sections.

Publication has increased since the initiation of funding and grants. With respect to general health research, publication in specific domains is on the rise, as evidenced by the fact that the number of articles and journals published from 1993 to 2003 reached 8,000.5 Increased sophistication is possible through bibliographic indicators, which are helpful for readers and potential scholars. These reflect the extent of institutional influence in communities. The most common forms of analysis are case studies, follow-up surveys and research programmes, which focus on specific issues and target the effective translation of knowledge to influence policy and practice. ${ }^{6}$ Funded research affects the policy section of a designed framework, especially as regards clinical practice and policies, which are also discussed in the context chosen in this work. We can also determine what factors affect policies and how important these factors are. These same questions likewise confront clinical practice. An intermediate outcome can express the success of changes to practice and policy. ${ }^{7}$ Final outcomes can be defined with consideration for a given level aspired for, such as minimum waiting time; such definition can advance the achievement of public policy outcomes. Beyond waiting time, concerns regarding the degree of compliance arise in various regional institutions, thereby affecting the overall status of health. Benefits related to the health sector have been categorised into two classes: health effects and public health. Strategic initiatives correlate with public health research; a case in point is the increase in epidemics in 2003-an occurrence that forced the research community to launch strategic initiatives to counter the outbreak of emergent infectious diseases. ${ }^{8}$

Another dimension of health and health benefits that affects both life quality and expectancy are medical advancements. Successful treatment is an outcome of new knowledge regarding disease prevention and intervention, the development of optimal treatment guidelines, professional training and skills development and the adoption of excellent protocols. The last three elements require the translation of knowledge as a major health research feature. ${ }^{9}$ Two other principal points are also highlighted in a few steps of the process that affects public health and health research; that is, new knowledge alone does not affect health impacts, and research is pervasive (gains and discovery association). In such situations, various actors claim success or partial success, but ascribing achievement to one agent is difficult as efforts arise from teamwork and recognising only a single individual would be inappropriate. This process is complex because of the involvement of multiple funding entities, long timelines and multiple organisations. ${ }^{10}$ Concentration should be devoted to outcomes that transcend the interests of specific stakeholders or contributors. Outcomes must be celebrated and enjoyed rather than allowed to create a divide. The logical approach is to measure and estimate gains from research at the organisational and team levels as this strategy encourages further funding. This approach also enables the measurement of both performance and impact. As a measurement, potential life years, on its own, is an ineffective tool for ascertaining various categories of diseases. ${ }^{11}$ More pragmatic considerations are required for ongoing health state indicators compiled through statistical evidence given that approximately 460,000 and 250,000 potential life years were lost to cancer and circulatory disease in 2001, respectively. For an advanced measurement of health state, a few other dimensions, such as life expectancy, life quality and health or quality-adjusted life expectancy, should also be considered and appropriately developed. 
Several factors contribute to the reduction of potential life years; these are including disease prevention, nonhealth determinants and management. For instance, the narrative/qualitative approach is best suited for cardiovascular disease, as experimented in the UK. ${ }^{12}$

This research followed the economic impact classification of Buxton. Economic effects are closely associated with return on invested funds. The economic benefits of research, such as productivity and increased earnings, are spread throughout a society and ultimately lead to workforce health gains. In a number of cases, these advantages result in the production of public goods, increased awareness of medical and dietary intake and improved surgical procedures. Discoveries also bring profits if research outcomes stimulate the manufacture of patented products. Sometimes, successful commercialisation is unclaimed by funding agencies or researchers. ${ }^{12}$ Funding encourages research commercialisation as studies count as intellectual property. Most companies working on health projects earn immense profits, yet there is currently no comprehensive presentation and exploration of value-added discoveries. Nevertheless, appropriate commercialisation indicators are under development. In the biotechnology field, for instance, small and medium-sized commercialisation programmes are under consideration by various funding agencies. The intellectual property of funding agencies also motivates the development of new companies, ${ }^{13}$ and health technology advances the evaluation of savings through the appropriate documentation of medications and cost-effectiveness. ${ }^{14}$ Defining cost-saving indicators is a promising approach that arises from agency funding of research projects. The human capital method of measuring value and earning potential is diminished by accidents and ill health. Disease burdens are repeatedly published by numerous agencies, complete with estimates and work plans. ${ }^{15}$ After work completion, estimations related to accident avoidance and ill health are possible. Disability periods can be estimated, as well, through research. Recent studies sought to measure medical advances on the basis of contribution to the gross domestic product (GDP). The experts involved in the present study believe that this method is beyond the scope of the proposed conceptual framework given that the GDP is dependent on multiple factors. Present accounting systems do not measure the health of a population. ${ }^{16}$

\section{CONCLUSION}

Health research funding and health research effects can be feasibly measured through an array of developed indicators. An important task is to formulate a conceptual framework that encompasses the effects identified by stakeholders and nature comprehension. After a framework is developed, related indicators can be identified. The framework established in the current work is designed to facilitate the pinpointing of specific initiatives that require a delicate approach. Under this framework, broader initiatives focus on societal innovations on treatment and prevention, and supporters and researchers share breakthroughs and credits. In this work, we targeted both performance evaluation and impact measurement. The most suitable route to achieving these tasks is collaborating with national and international agencies that have health-related stakes and referring to available literature and statistical data in the development of appropriate indicators. This research emphasised the complex obstacles to devising suitable approaches for performance and impact measurement. Complexity arises from the fact that no single method suits every stakeholder's policy and mandate. However, the responsibility is clear when it comes to high performance and considerable effects.

\section{CONFLICTS OF INTERESTS}

The authors have no conflicts of interests to declare.

\section{FUNDING}

None.

\section{REFERENCES}

[1]. Minh HV et al. "Health system research in Vietnam: generating policy-relevant knowledge." Global public health vol. 10 Supppl 1,0 1. 2015: S1-4.

[2]. AnChiu C, Xian W, Moss CF. Flying in silence: echolocating bats cease vocalizing to avoid sonar jamming. Proceedings of the National Academy of Sciences of the United States of America; 2008. 105(35): p. 13116-21.

[3]. World Health Organization. Western Pacific Regional Framework for Action for Disaster Risk management for Health. 2015. 
[4]. Graham, Kathryn ER, et al. Evaluating health research impact: Development and implementation of the Alberta Innovates-Health Solutions impact framework. Research Evaluation 21.5. 2012; 354-367.

[5]. Marmot, M., \& Friel,. (2008). Global health equity: evidence for action on the social determinants of health. Journal of Epidemiology \& Community Health, 62(12), 1095-1097.

[6]. Gill CJ., et al. "The mCME Project: a randomized controlled trial of an SMS-based continuing medical education intervention for improving medical knowledge among Vietnamese community-based physicians' assistants." PLoS One 11.11. 2016: e0166293.

[7]. World Health Organization, UNICEF, IBFAN. Marketing of breast-milk substitutes: National implementation of the international code Status Report 2016. 2016.

[8]. De Neve, J.-W. and G. Fink. Children's education and parental old age survival - Quasi-experimental evidence on the intergenerational effects of human capital investment. Journal of Health Economics 2018; 58: 76-89.

[9]. Hong, T. T., et al. Completeness and reliability of mortality data in Viet Nam: Implications for the national routine health management information system. PLOS ONE (2018); 13(1): e0190755.

[10]. Jiang, F., et al. Artificial intelligence in healthcare: past, present and future. Stroke and Vascular Neurology 2017; 2(4): 230.

[11]. Cleland, J., et al. The promotion of intrauterine contraception in low- and middle-income countries: a narrative review. Contraception (2017); 95(6): 519-528.

[12]. Nabyonga-Orem J. Monitoring Sustainable Development Goal 3: how ready are the health information systems in low-income and middle-income countries?. BMJ Glob Health. 2017;2(4):e000433.

[13]. Schram A, et al. The role of trade and investment liberalization in the sugar-sweetened carbonated beverages market: a natural experiment contrasting Vietnam and the Philippines. Glob Health. 2015; 11(1):41.

[14]. Witter S. 'Doi Moi' and health: the effect of economic reforms on the health system in Vietnam. Int J Health Plan Manag. 1996; 11(2):159-72.

[15]. Smith W, Darko E. Social enterprise: constraints and opportunities-evidence from Vietnam and Kenya. [Online] 2014 ODI. www. odi. org/publications/8303-social-enterprise-constraintsopportunitiesevidence-vietnam-kenya.

[16]. Godfrey-Faussett P, et al. Why do patients with a cough delay seeking care at Lusaka urban health centres? A health systems research approach. Int J Tuberc Lung Dis. 2002; 6(9):796-805. 